\title{
Life satisfaction and mortality in elderly people: The Kangwha Cohort Study
}

\author{
Heejin Kimm', Jae Woong Sull ${ }^{2,5^{*}}$, Bayasgalan Gombojav', Sang-Wook Yi ${ }^{3}$ and Heechoul Ohrr ${ }^{4}$
}

\begin{abstract}
Background: As well as biomedical risk factors, psychological factors have been reported to be related to mortality rate. The purpose of this study was to examine the relationship between life satisfaction and mortality in elderly people through an 11.8-year follow-up study of a prospective cohort.

Methods: Among 3,600 participants of the Kangwha Cohort Study who survived in 1994, 1,939 respondents of the Life Satisfaction Index (LSI)-A questionnaire were included (men, 821; women, 1118). The mortality risk for the period up to December 2005 was measured using the Cox Proportional Hazard Model.

Results: When the relationship between LSI and mortality was evaluated in men, the unsatisfied group with lower LSI scores showed a significantly higher risk of all-cause mortality (hazard ratio [HR], 1.42; 95\% confidence interval $[C I], 1.11-1.83)$ than the satisfied group with higher LSI scores. In women, the unsatisfied group showed a significantly higher risk of all-cause mortality $(\mathrm{HR}, 1.51 ; 95 \% \mathrm{Cl}, 1.18-1.92)$ and cardiovascular mortality $(\mathrm{HR}, 2.23 ; 95 \%$ Cl, 1.30-3.85) than the satisfied group.
\end{abstract}

Conclusion: We found that elderly people with a lower LSI score, regardless of gender, were at risk of increased mortality from all causes, and low LSI score was also associated with cardiovascular mortality.

Keywords: Life satisfaction, Elderly, Mortality, Cardiovascular disease, Quality of life

\section{Background}

Psychological factors and well-being, with no physical risks involved, have been reported to be associated with mortality rates [1-5]. Two Finnish studies found in a 20year follow-up that people with a low self-reported life satisfaction index (LSI) showed an increased risk of mortality and suicide [4,5]. The relationship between life satisfaction and mortality risk has been examined mostly in Western people; e.g., Finnish elderly people in their 80 s and Germans [6,7]. However, a recent Taiwanese study also indicated that life satisfaction is an independent mortality risk factor [8].

In a Finnish prospective study, life satisfaction was associated with a risk of total death in men, but only injury death in women [4]. The Finnish study categorized deaths into total death, disease death, and injury death. Two other socio-epidemiological studies also

\footnotetext{
* Correspondence: jsull@eulji.ac.kr

${ }^{2}$ Department of Biomedical Laboratory Science, College of Health Sciences,

Eulji University, Seongnam, Korea

Full list of author information is available at the end of the article
}

showed that indicators of impaired quality of life are related to high levels of cardiovascular risk factors and high prevalence of overt cardiovascular disease [9]. In fact, there are few relevant studies that classified causes of deaths by disease $[8,9]$. In this study, we followed up a prospective cohort of community elderly residents for 11.8 years, and examined the relationship between life satisfaction and risk of mortality from all causes, cardiovascular disease, and cancer in men and women after adjusting for the influences of various known risk factors.

\section{Methods}

\section{Study population}

The primary survey for the Kangwha Cohort was conducted in March 1985 [10,11]. Kangwha County is a rural island in South Korea located $50 \mathrm{~km}$ from Seoul with a mostly agricultural population. Its population size was 71,116 in 1993 [11]. The number of Kangwha County residents who were $\geq 55$ years of age in February 1985 was 9,378 . Among them, $67.9 \%$ (or 6,372
Ciomed Central

(c) 2012 Kimm et al; licensee BioMed Central Ltd. This is an Open Access article distributed under the terms of the Creative Commons Attribution License (http://creativecommons.org/licenses/by/2.0), which permits unrestricted use, distribution, and reproduction in any medium, provided the original work is properly cited. 
residents) participated in the primary survey. In March 1994, the secondary survey, including interviews for demographic characteristics, Mini-Mental State Examination (MMSE), Activities of Daily Living (ADL), and Instrumental Activities of Daily Living (IADL), as well as LSI, was carried out. Body height and weight were measured by trained investigators. Body mass index (BMI) was calculated as the ratio of weight (in kilograms) to height (in meters) squared. This study used data from the secondary survey of the Kangwha Cohort. During the 9-year interval, from March 1985 to March 1994, there were 2,772 deaths, and 3,600 participants survived at the secondary survey in March 1994. Of these, we excluded those who were not followed after the initial survey $(n=13)$, those who had a stroke or coronary heart disease before the initial survey $(n=23)$, and those who had no LSI $(\mathrm{n}=1219)$, ADL/IADL $(\mathrm{n}=$ $113)$, or BMI/MMSE $(\mathrm{n}=293)$ data. Thus, the final study population recruited included 1,939 individuals (53.9\%, 821 males and 1,118 females). They were followed up for mortality over a maximum of 11.8 years until December 31, 2005. The Institutional Review Board of Human Research of Yonsei University approved the study (approval no. 4-2007-0182).

\section{Baseline data collection}

The investigation team interviewed each subject using a structured questionnaire for demographic characteristics, including age, sex, education, chronic disease conditions, health behaviors (smoking and drinking), MMSE, ADL, IADL, and LSI. Life satisfaction was assessed by the LSI-A index, which was first prepared, validated, and published by Neugarten et al. [12]. The internal consistency reliability coefficient (Cronbach's alpha) was computed at 0.82 in a Korean study with 600 elderly subjects [13]. Of the 20 items in the questionnaire, 12 items were positively worded; 0,1 , and 2 points were assigned to "disagree," "don't know," and "agree" answers, respectively. Eight items were negatively worded with 0 points assigned to the "agree" answer. The scores that could be achieved from LSI-A ranged between 0 and 40 points. Cognitive function was measured using the MMSE [14]. The MMSE test included questions for the following categories: orientation to time, orientation to place, repetition and registration, attention and calculation, recall, naming, repetition, comprehension, reading, writing, and drawing. MMSE scores ranged from 0 to 30 . The cut points defined in previous studies were used to categorize the MMSE scores [15,16]. Cognitively impaired persons were defined as those who had a MMSE score below 15.

Disability in ADL was evaluated by the following criteria: bathing or showering, dressing, going to the toilet, transferring (in and out of bed or chair), and eating
[17]. For the performance of these activities, participants were asked to answer in one of three categories: perform the activity independently, perform the activity with assistance, and unable to perform the activity. ADL disability was defined as being unable to perform the activity. In other words, if there was an answer of "unable to perform the activity" for any of the seven ADL questions, the respondent was defined as having disability in ADL. In order to define IADL, the following activities were addressed: housework, meal preparation, traveling via car or public transportation, food or clothes shopping (regardless of transport), medication use (preparing and taking correct dose), making telephone calls, and managing money [18]. Each activity was graded on a three-part scale: independent, assistance needed, and dependent. Participants who performed an activity dependently or with assistance were considered as having IADL disability. In other words, if there was an answer of "unable to perform the activity" for any of the 14 IADL questions, the respondent was defined to have disability in IADL. For chronic conditions, study subjects were asked to answer yes or no to the question: "Do you have any chronic disease or past accident or injury for which you feel uncomfortable in your daily lives, including work?"

\section{Outcome assessment}

The outcomes of this research were cause-specific deaths. Data on deaths and their causes from March 1, 1994 to December 31, 2005 were obtained from the Statistics on the Causes of Death in Korea by the Korea National Statistical Office. The International Classification of Diseases, 10th Revision was applied to define the causes of death (I10 to I25 and I60 to I74 for cardiovascular disease, C00-C97.9 for cancer).

\section{Statistical analysis}

LSI scores were grouped into tertiles using the dataset for men and women $(\mathrm{N}=1939)$ to represent 'satisfied' (26-40 points), 'intermediate' (16-25 points), and 'unsatisfied' (0-15 points). Analysis of variance (ANOVA) and chi-square test were used to analyze the statistical differences among the characteristics of the study participants. Because there could be a variation in mortality risk by gender, a stratified analysis was made for men and women.

We used the Cox proportional hazard model to test the relationship between LSI at baseline and subsequent risk of total mortality. Three models were set up to adjust for confounding variables. In Model I, age as a continuous variable was adjusted for. In Model II, in addition to age, the history of chronic disease (ever, never), smoking habits (never, former, 1-19 tobacco/day, and $\geq 20$ tobacco/day), alcohol consumption, BMI (as a 
continuous variable), and education status (no education, elementary, high) were adjusted for. Smoking status and education level were included in the models as dummy variables. In Model III, IADL (normal, abnormal) was further adjusted for. Hazard ratios (HRs) and 95\% confidence intervals (CIs) were expressed for the results. A significance level of $p<0.05$ was used for all tests. Analyses were performed with SAS Windows version 9.1.

\section{Results}

General characteristics of men and women by LSI level are presented in Tables 1 and 2. Mean age was not different between LSI groups in both men and women. In men, the unsatisfied group had significantly more incidences of chronic disease than the satisfied group ( $p$ $<0.01$ ) (Table 1). The unsatisfied group of men was also significantly less educated $(p<0.01)$, had lower cognitive function, and had more disability in ADL and IADL. In women, although the outcome for IADL was similar to that in men, ADL, cognitive function, and education status were not related with LSI (Table 2). However, smoking, BMI, and chronic disease were significantly associated with LSI in women.

Table 3 shows the relationship between LSI and mortality in men. After adjusting for age, the unsatisfied group's HR of all-cause mortality, compared to the satisfied group, was 1.61 (95\% CI, 1.26-2.04). In Model II, the HR was 1.50 (95\% CI, 1.18-1.92). After further adjusting for IADL in Model III, the HR was 1.42 (95\%

Table 1 Baseline characteristics of the study population in the Kangwha Cohort Study in Korean men, according to the LSI

\begin{tabular}{|c|c|c|c|c|}
\hline \multirow{4}{*}{ Characteristics } & \multicolumn{3}{|c|}{ LSI $(\mathrm{N}=821)$} & \multirow[t]{4}{*}{$\mathrm{F}$ or $\chi 2$ value } \\
\hline & Satisfied & Intermediate & Unsatisfied & \\
\hline & $26-40$ & $16-25$ & 0-15 & \\
\hline & $(\mathrm{N}=281)$ & $(\mathrm{N}=316)$ & $(\mathrm{N}=224)$ & \\
\hline & Mean \pm SD & Mean \pm SD & Mean \pm SD & \\
\hline Age (years) & $73.2 \pm 5.5$ & $72.8 \pm 5.3$ & $73.4 \pm 5.2$ & 1.01 \\
\hline \multirow[t]{2}{*}{ BMI $\left(\mathrm{kg} / \mathrm{m}^{2}\right)$} & $21.5 \pm 2.8$ & $21.3 \pm 3.1$ & $20.9 \pm 2.8$ & $3.06^{*}$ \\
\hline & N (\%) & N (\%) & N (\%) & \\
\hline Chronic disease $^{a}$ & & & & $15.8^{* *}$ \\
\hline Never & $192(68.3)$ & $205(64.9)$ & $116(51.8)$ & \\
\hline Ever & $89(31.7)$ & $111(35.1)$ & $108(48.2)$ & \\
\hline Education & & & & $14.9^{* *}$ \\
\hline No & $80(28.5)$ & $93(29.4)$ & $95(42.4)$ & \\
\hline Elementary & $180(64.1)$ & $192(60.8)$ & $115(51.3)$ & \\
\hline High & $21(7.5)$ & $31(9.8)$ & $14(6.3)$ & \\
\hline Smoking & & & & 7.29 \\
\hline Never & $82(29.2)$ & $68(21.5)$ & $51(22.8)$ & \\
\hline Former & $47(16.7)$ & $58(18.4)$ & $42(18.8)$ & \\
\hline \multicolumn{5}{|l|}{ Current } \\
\hline 1-19 tobacco/day & $76(27.1)$ & $81(25.6)$ & $63(28.1)$ & \\
\hline$\geq 20$ tobacco/day & $76(27.1)$ & $109(34.5)$ & $68(30.4)$ & \\
\hline Alcohol drinking & & & & 4.20 \\
\hline Non-drinkers & $132(47.0)$ & $129(40.8)$ & $86(38.4)$ & \\
\hline Drinkers & $149(53.0)$ & $187(59.2)$ & $138(61.6)$ & \\
\hline Cognitive impairment & & & & $6.33^{*}$ \\
\hline Normal $(\geq 15)$ & $271(96.4)$ & $295(93.4)$ & $204(91.1)$ & \\
\hline Impairment $(<15)$ & $10(3.6)$ & $21(6.6)$ & $20(8.9)$ & \\
\hline $\mathrm{ADL}$ & & & & $9.78^{* *}$ \\
\hline Normal & $281(100.0)$ & $315(99.7)$ & $219(97.8)$ & \\
\hline Abnormal & $0(0.0)$ & $1(0.3)$ & $5(2.2)$ & \\
\hline IADL & & & & $21.8^{* *}$ \\
\hline Normal & $169(60.1)$ & $164(51.9)$ & $88(39.3)$ & \\
\hline Abnormal & $112(39.9)$ & $152(48.1)$ & $136(60.7)$ & \\
\hline
\end{tabular}

${ }^{*} p<0.05,{ }^{* *} p<0.01$

${ }^{a}$ Study participants were asked to answer yes or no to the question: "Do you have any chronic disease or past accident or injury for which you feel uncomfortable in your daily lives, including work?" 
Table 2 Baseline characteristics of the study population in the Kangwha Cohort Study in Korean women, according to the LSI

\begin{tabular}{|c|c|c|c|c|}
\hline \multirow[b]{2}{*}{ Characteristics } & \multicolumn{3}{|c|}{$\begin{array}{c}\text { LSI } \\
(\mathrm{N}=1118)\end{array}$} & \multirow[t]{2}{*}{$\begin{array}{c}\text { F or } \\
\chi^{2} \\
\text { value }\end{array}$} \\
\hline & $\begin{array}{l}\text { Satisfied } \\
26-40 \\
(\mathrm{~N}= \\
380)\end{array}$ & $\begin{array}{c}\text { Intermediate } \\
\qquad \begin{array}{c}16-25 \\
(N=376)\end{array}\end{array}$ & $\begin{array}{l}\text { Unsatisfied } \\
\qquad \begin{array}{l}0-15 \\
(\mathrm{~N}=362)\end{array}\end{array}$ & \\
\hline & $\begin{array}{l}\text { Mean } \pm \\
\text { SD }\end{array}$ & Mean \pm SD & Mean \pm SD & \\
\hline Age (years) & $73.5 \pm 6.2$ & $73.1 \pm 6.0$ & $73.3 \pm 5.9$ & 0.42 \\
\hline BMI $\left(\mathrm{kg} / \mathrm{m}^{2}\right)$ & $\begin{array}{c}22.8 \pm 3.6 \\
N(\%)\end{array}$ & $\begin{array}{c}22.1 \pm 3.4 \\
N(\%)\end{array}$ & $\begin{array}{c}22.3 \pm 3.9 \\
N(\%)\end{array}$ & $3.63^{*}$ \\
\hline Chronic disease $^{a}$ & & & & $6.34^{*}$ \\
\hline Never & $251(65.0)$ & $227(60.4)$ & $207(57.2)$ & \\
\hline Ever & $129(34.0)$ & $149(39.6)$ & $155(42.8)$ & \\
\hline Education & & & & 5.60 \\
\hline No & $282(74.2)$ & $292(77.7)$ & $285(78.7)$ & \\
\hline Elementary & $96(25.3)$ & $80(21.3)$ & $71(19.6)$ & \\
\hline High & $2(0.5)$ & $4(1.1)$ & $6(1.7)$ & \\
\hline Smoking & & & & $17.6^{* *}$ \\
\hline Never & $334(87.9)$ & $315(83.8)$ & $280(77.4)$ & \\
\hline Former & $4(1.1)$ & $8(2.1)$ & $14(3.9)$ & \\
\hline \multicolumn{5}{|l|}{ Current } \\
\hline $\begin{array}{l}1-19 \\
\text { tobacco/day }\end{array}$ & $33(8.7)$ & $40(10.6)$ & $56(15.5)$ & \\
\hline $\begin{array}{l}\geq 20 \text { tobacco/ } \\
\text { day }\end{array}$ & $9(2.4)$ & $13(3.5)$ & $12(3.3)$ & \\
\hline Alcohol drinking & & & & 0.88 \\
\hline Non-drinkers & 348 (91.6) & $338(89.9)$ & $325(89.8)$ & \\
\hline Drinkers & $32(8.4)$ & $38(10.1)$ & $37(10.2)$ & \\
\hline Cognitive impairment & & & & 2.43 \\
\hline Normal $(\geq 15)$ & $286(75.3)$ & $287(76.3)$ & $259(71.6)$ & \\
\hline Impairment $(<15)$ & $94(24.7)$ & 89 (23.7) & $103(28.4)$ & \\
\hline $\mathrm{ADL}$ & & & & 0.70 \\
\hline Normal & 377 (99.2) & $371(98.7)$ & $359(99.2)$ & \\
\hline Abnormal & $3(0.8)$ & $5(1.3)$ & $3(0.8)$ & \\
\hline IADL & & & & $9.26^{* *}$ \\
\hline Normal & $157(41.3)$ & $146(38.8)$ & $112(30.9)$ & \\
\hline Abnormal & $223(58.7)$ & $230(61.2)$ & $250(69.1)$ & \\
\hline
\end{tabular}

${ }^{*} p<0.05,{ }^{* *} p<0.01$

${ }^{a}$ Study participants were asked to answer yes or no to the question: "Do you have any chronic disease or past accident or injury for which you feel uncomfortable in your daily lives, including work?"

CI, 1.11-1.83). The HR of cardiovascular mortality in Model II was 1.80-fold higher in the unsatisfied group (95\% CI, 1.02-3.16) than in the satisfied group. After additionally adjusting for IADL, the HR was still higher, but the result was not significant (HR, 1.63; 95\% CI, 0.92-2.89).

Table 4 shows the relationship between LSI and mortality in women. After additionally adjusting for IADL in
Table 3 Number of deaths and adjusted hazard ratios of death according to LSI among Korean men

\begin{tabular}{|c|c|c|c|}
\hline \multirow[b]{2}{*}{ Cause of death } & \multicolumn{3}{|c|}{ LSI } \\
\hline & $\begin{array}{l}\text { Satisfied } \\
26-40 \\
(N=281)\end{array}$ & $\begin{array}{c}\text { Intermediate } \\
\begin{array}{c}16-25 \\
(\mathrm{~N}=316)\end{array}\end{array}$ & $\begin{array}{l}\text { Unsatisfied } \\
\qquad \begin{array}{l}0-15 \\
(\mathrm{~N}=224)\end{array}\end{array}$ \\
\hline \multicolumn{4}{|l|}{ All causes } \\
\hline No. of deaths & 130 & 186 & 138 \\
\hline $\mathrm{HR}(95 \% \mathrm{Cl})^{\mathrm{a}}$ & 1.00 & 1.51 (1.20-1.89) & $1.61(1.26-2.04)$ \\
\hline $\operatorname{HR}(95 \% \mathrm{Cl})^{\mathrm{b}}$ & 1.00 & $1.49(1.19-1.87)$ & $1.50(1.18-1.92)$ \\
\hline $\operatorname{HR}(95 \% \mathrm{Cl})^{\mathrm{C}}$ & 1.00 & $1.45(1.16-1.82)$ & $1.42(1.11-1.83)$ \\
\hline \multicolumn{4}{|c|}{ Cardiovascular disease } \\
\hline No. of deaths & 24 & 28 & 27 \\
\hline $\mathrm{HR}(95 \% \mathrm{CI})^{\mathrm{a}}$ & 1.00 & $1.23(0.71-2.13)$ & $1.74(1.00-3.01)$ \\
\hline $\operatorname{HR}(95 \% \mathrm{Cl})^{\mathrm{b}}$ & 1.00 & $1.18(0.68-2.04)$ & $1.80(1.02-3.16)$ \\
\hline $\operatorname{HR}(95 \% \mathrm{Cl})^{\mathrm{C}}$ & 1.00 & $1.12(0.65-1.94)$ & $1.63(0.92-2.89)$ \\
\hline \multicolumn{4}{|l|}{ Cancer } \\
\hline No. of deaths & 30 & 41 & 26 \\
\hline $\mathrm{HR}(95 \% \mathrm{CI})^{\mathrm{a}}$ & 1.00 & $1.33(0.83-2.13)$ & $1.29(0.76-2.18)$ \\
\hline $\operatorname{HR}(95 \% \mathrm{Cl})^{\mathrm{b}}$ & 1.00 & $1.27(0.79-2.04)$ & $1.19(0.70-2.05)$ \\
\hline $\operatorname{HR}(95 \% \mathrm{Cl})^{\mathrm{c}}$ & 1.00 & $1.29(0.80-2.08)$ & $1.24(0.72-2.15)$ \\
\hline
\end{tabular}

Notes: $H R$ hazard ratio, $\mathrm{Cl}$ confidence interval

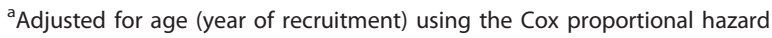
model

${ }^{\mathrm{b}}$ Adjusted for age (year of recruitment), history of chronic disease, smoking habits (never, former, 1-19 tobacco/day, and $\geq 20$ tobacco/day), alcohol drinking, body mass index, and education level using the Cox proportional hazard model

${ }^{\mathrm{C}}$ Added IADL as covariates in the Cox proportional hazard model

Model III, the unsatisfied group had a significantly higher risk of all-cause mortality (HR, 1.51; 95\% CI, 1.18-1.92) and cardiovascular mortality (HR, 2.23; 95\% CI, 1.30-3.85) than the satisfied group. In both men and women, however, no significant relationship between LSI and cancer mortality risk was observed.

\section{Discussion and Conclusions}

In this prospective cohort study of Korean elderly subjects, low life satisfaction was associated with long-term mortality. It was also associated with cardiovascular disease-related mortality. These data are largely consistent with the findings of previous studies, such as a Finnish prospective study [4], a Finnish study of elderly people in their 80s [6], a Berlin aging study [7], and a Taiwanese prospective study [8]. The Finnish prospective study showed that low life satisfaction was associated with the increased risk of total death in men, but only of injury death in women [4]. In contrast, the present study shows that the relationship between low life satisfaction and mortality risk was significant in both men and women. Many previous studies of LSI and mortality categorized deaths into total death, disease death, and injury death, whereas the present study evaluated the relationship according to the specific diseases that 
Table 4 Number of deaths and adjusted hazard ratios of death according to LSI among Korean women

\begin{tabular}{|c|c|c|c|}
\hline \multirow[b]{2}{*}{ Cause of death } & \multicolumn{3}{|c|}{ LSI } \\
\hline & $\begin{array}{l}\text { Satisfied } \\
26-40 \\
(N=380)\end{array}$ & $\begin{array}{c}\text { Intermediate } \\
16-25 \\
(N=376)\end{array}$ & $\begin{array}{l}\text { Unsatisfied } \\
\quad 0-15 \\
(\mathrm{~N}=362)\end{array}$ \\
\hline \multicolumn{4}{|l|}{ All causes } \\
\hline No. of deaths & 126 & 146 & 155 \\
\hline $\mathrm{HR}(95 \% \mathrm{Cl})^{\mathrm{a}}$ & 1.00 & $1.33(1.05-1.69)$ & $1.61(1.27-2.03)$ \\
\hline $\operatorname{HR}(95 \% \mathrm{Cl})^{\mathrm{b}}$ & 1.00 & $1.30(1.02-1.65)$ & $1.53(1.20-1.95)$ \\
\hline $\operatorname{HR}(95 \% \mathrm{Cl})^{\mathrm{C}}$ & 1.00 & $1.30(1.02-1.66)$ & $1.51(1.18-1.92)$ \\
\hline \multicolumn{4}{|c|}{ Cardiovascular disease } \\
\hline No. of deaths & 21 & 34 & 38 \\
\hline $\operatorname{HR}(95 \% \mathrm{Cl})^{\mathrm{a}}$ & 1.00 & $1.83(1.06-3.15)$ & $2.28(1.34-3.89)$ \\
\hline $\operatorname{HR}(95 \% \mathrm{Cl})^{\mathrm{b}}$ & 1.00 & $1.84(1.07-3.19)$ & $2.28(1.32-3.91)$ \\
\hline HR $(95 \% \mathrm{CI})^{\mathrm{C}}$ & 1.00 & $1.84(1.07-3.18)$ & $2.23(1.30-3.85)$ \\
\hline \multicolumn{4}{|l|}{ Cancer } \\
\hline No. of deaths & 13 & 19 & 13 \\
\hline HR $(95 \% C l)^{a}$ & 1.00 & $1.53(0.76-3.10)$ & $1.16(0.54-2.49)$ \\
\hline $\operatorname{HR}(95 \% \mathrm{Cl})^{\mathrm{b}}$ & 1.00 & $1.49(0.73-3.03)$ & $1.09(0.50-2.38)$ \\
\hline $\operatorname{HR}(95 \% \mathrm{Cl})^{\mathrm{C}}$ & 1.00 & $1.47(0.72-2.98)$ & $1.06(0.48-2.31)$ \\
\hline
\end{tabular}

Notes: $H R$ hazard ratio, $\mathrm{Cl}$ confidence interval

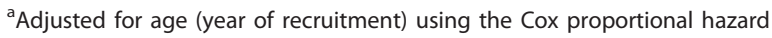
model

${ }^{\mathrm{b}}$ Adjusted for age (year of recruitment), history of chronic disease, smoking habits (never, former, 1-19 tobacco/day, and $\geq 20$ tobacco/day), alcohol drinking, body mass index, and education level using the Cox proportional hazard model

${ }^{\mathrm{C}}$ Added IADL as covariates in the Cox proportional hazard model

caused deaths. The present study shows that LSI was associated with a risk of cardiovascular disease, but not of cancer. The outcome suggests a strong relationship between life satisfaction and cardiovascular disease.

The present study used the LSI-A, a 20-item questionnaire, as an assessment tool of quality of life satisfaction. The Taiwanese study also used the LSI-A, and it is known to be useful in assessing overall quality of life satisfaction [8]. Previous studies found that self-reported life satisfaction was associated with cognitive function, formal support, social interaction, social relationships, socioeconomic status, age, marital status, health status, religion, economic status, and/or living arrangements [19-25]. The present study also found that life satisfaction was associated with chronic disease conditions, education level, cognitive function, and disability in ADL and IADL in Korean elderly men.

This study has several limitations. First, we adjusted BMI as a covariate. However, other classical biological risk factors for cardiovascular-related death, such as hypertension, diabetes, and dyslipidemia, were not included in this study. Second, non-inclusion of variables, such as depressive symptoms, sense of wellbeing, and social support, may be a limitation, although well-being is a dimension measured by the
LSI-A in a comprehensive sense. Third, deaths from diseases other than cardiovascular disease, cancer, and all causes could not be analyzed due to an insufficient number of cases. More causes of death need to be analyzed in further studies. Fourth, selection bias is often an issue in studies of life satisfaction. The subjects in this study were an elderly group residing in the same administrative and geographical community, and approximately $85 \%$ of them engaged in agriculture, thus there was a great social and cultural similarity among them.

In conclusion, our findings indicate an association between low life satisfaction and long-term mortality among elderly people, in particular cardiovascular disease mortality. Further studies are necessary to describe the relationship between life satisfaction and mortality risk for a wider range of diseases.

\section{Abbreviations}

ADL: Activities of Daily Living; BMI: Body mass index; Cl: Confidence interval; HR: Hazard ratio; IADL: Instrumental Activities of Daily Living; LSI: Life Satisfaction Index; MMSE: Mini-mental state examination.

\section{Acknowledgements}

Work was supported by the Korea Science and Engineering Foundation (KOSEF: R-01-1993-000-00073-0) grant funded by the Korea government (MOST).

\section{Author details}

${ }^{1}$ Institute for Health Promotion \& Department of Epidemiology and Health Promotion, Graduate School of Public Health, Yonsei University, Seoul, Korea. ${ }^{2}$ Department of Biomedical Laboratory Science, College of Health Sciences, Eulji University, Seongnam, Korea. ${ }^{3}$ Department of Preventive Medicine and Public Health, Kwandong University College of Medicine, Gangneung, Korea. ${ }^{4}$ Department of Preventive Medicine, Yonsei University College of Medicine, Seoul, Korea. ${ }^{5}$ Department of Biomedical Laboratory Science, College of Health Science, Eulji University, 212, Yangji-dong, Sujoung-gu, Sungnam-Si, Gyeongi-Do 461-713, Korea.

\section{Authors' contributions}

All authors participated in drafting of the manuscript. HK performed the analysis and interpretation of data. JWS participated in planning the design and interpretation of data. BG and SWY participated in data analyses and interpretation. $\mathrm{HO}$ conceived the idea of the study, planned the design, collected data, and participated in interpretation of the data. All authors read and approved the final manuscript.

\section{Competing interests}

The authors declare that they have no competing interests.

Received: 7 September 2011 Accepted: 19 January 2012

Published: 19 January 2012

\section{References}

1. Lacruz ME, Emeny RT, Baumert J, Ladwig KH: Prospective association between self-reported life satisfaction and mortality: Results from the MONICA/KORA Augsburg S3 Survey Cohort Study. BMC Public Health 2011.

2. Chida Y, Steptoe A: Positive psychological well-being and mortality: a quantitative review of prospective observational studies. Psychosom Med 2008, 70:741-756.

3. Rai D, Kosidou K, Lundberg M, Araya R, Lewis G, Magnusson C: Psychological distress and risk of long-term disability: population-based longitudinal study. J Epidemiol Community Health 2010. 
4. Koivumaa-Honkanen $\mathrm{H}$, Honkanen R, Viinamäki H, Heikkilä K, Kaprio J, Koskenvuo M: Self-reported life satisfaction and 20-year mortality in healthy Finnish adults. Am J Epidemiol 2000, 152:983-991.

5. Koivumaa-Honkanen $\mathrm{H}$, Honkanen R, Viinamäki H, Heikkilä K, Kaprio J, Koskenvuo M: Life satisfaction and suicide: a 20-year follow-up study. Am J Psychiatry 2001, 158:433-439.

6. Lyyra TM, Törmäkangas TM, Read S, Rantanen T, Berg S: Satisfaction with present life predicts survival in octogenarians. J Gerontol B Psychol Sci SoC Sci 2006, 61:P319-P326.

7. Maier H, Smith J: Psychological predictors of mortality in old age. $J$ Gerontol B Psychol Sci Soc Sci 1999, 54:P44-P54.

8. Collins AL, Glei DA, Goldman N: The role of life satisfaction and depressive symptoms in all-cause mortality. Psychol Aging 2009, 24:696-702.

9. Siegrist J: Impaired quality of life as a risk factor in cardiovascular disease. J Chronic Dis 1987, 40:571-578.

10. Sull JW, Yi SW, Nam CM, Choi K, Ohrr H: Binge drinking and hypertension on cardiovascular disease mortality in korean men and women: A kangwha cohort study. Stroke 2010, 41:2157-2162.

11. Sull JW, Yi SW, Nam CM, Ohrr H: Binge drinking and mortality from all causes and cerebrovascular diseases in korean men and women: A kangwha cohort study. Stroke 2009, 40:2953-2958.

12. Neugarten BL, Havighurst RJ, Tobin SS: The measurement of life satisfaction. J Gerontol 1961, 16:134-143.

13. Kim SH: A study on type of leisure activities, motor fitness, and life satisfaction in old woman. Korean J Sports Science 2006, 15:75-84.

14. Folstein MF, Folstein SE, McHugh PR: "Mini-mental state". A practical method for grading the cognitive state of patients for the clinician. $J$ Psychiatr Res 1975, 12:189-198.

15. Bassuk SS, Wypij D, Berkman LF: Cognitive impairment and mortality in the community-dwelling elderly. Am J Epidemiol 2000, 151:676-688.

16. Andersen K, Nybo H, Gaist D, Petersen HC, McGue M, Jeune B, Vaupel JW, Christensen K: Cognitive impairment and mortality among nonagenarians: The danish 1905 cohort survey. Dement Geriatr Cogn Disord 2002, 13:156-163.

17. Katz S, Ford AB, Moskowitz RW, Jackson BA, Jaffe MW: Studies of illness in the aged. The index of ADL: A standardized measure of biological and psychosocial function. JAMA 1963, 185:914-919.

18. Lawton MP, Brody EM: Assessment of older people: Self-maintaining and instrumental activities of daily living. Gerontologist 1969, 9:179-186.

19. Jones TG, Rapport LJ, Hanks RA, Lichtenberg PA, Telmet K: Cognitive and psychosocial predictors of subjective well-being in urban older adults. Clin Neuropsychol 2003, 17:3-18.

20. Krause N: Perceived health problems, formal/informal support and life satisfaction among older adults. J Gerontol 1990, 45:S193-S205.

21. Sparks M, Zehr D, Painter B: Predictors of life satisfaction: Perceptions of older community-dwelling adults. J Gerontol Nurs 2004, 38:47-53.

22. McCamish-Svensson C, Samuelson G, Hagberg B, Svensson T, Dehlin O: Social relationship and health as predictors of life satisfaction in advanced old age: Results from a Swedish longitudinal study. Int J Aging Hum Dev 1999, 48:301-324

23. Usuni WM, Keli TJ, Durig KR: Socioeconomic comparisons and life satisfaction of elderly adults. J Gerontol 1985, 40:110-114.

24. Jung M, Muntaner C, Choi M: Factors related to perceived life satisfaction among the elderly in South Korea. J Prev Med Public Health 2010, 43:292-300.

25. An JY, An K, O'Connor L, Wexler S: Life satisfaction, self-esteem, and perceived health status among elder Korean women: Focus on living arrangements. J Transcult Nurs 2008, 19:151-160.

\section{Pre-publication history}

The pre-publication history for this paper can be accessed here: http://www.biomedcentral.com/1471-2458/12/54/prepub

doi:10.1186/1471-2458-12-54

Cite this article as: Kimm et al.: Life satisfaction and mortality in elderly people: The Kangwha Cohort Study. BMC Public Health 2012 12:54.

\section{Submit your next manuscript to BioMed Central and take full advantage of:}

- Convenient online submission

- Thorough peer review

- No space constraints or color figure charges

- Immediate publication on acceptance

- Inclusion in PubMed, CAS, Scopus and Google Scholar

- Research which is freely available for redistribution

Submit your manuscript at www.biomedcentral.com/submit 